\title{
Developing a Digital Libraries Master's Programme
}

\author{
Elena Macevičiūtè, Tom Wilson, and Helena Francke \\ Swedish School of Library and Information Science, University of Borås, \\ Allégatan 1, Borås, 50190, Sweden \\ \{elena.maceviciute, wilsontd\}@gmail.com, helena.francke@hb.se \\ http: //www.hb.se/
}

\begin{abstract}
The changes in Swedish education following the Bologna requirements resulted in the first Master's programmes in Library and Information Science. Two of them target information professionals working with digital resources and services and seeking to develop and update their knowledge. One programme is oriented to foreign students from all over the world, another to Swedish students. A Venn diagram illustrating the relationships among the elements of LIS was used to develop the curriculum for the international Master's programmes in Digital Libraries and Information Services. As this programme is delivered in distance learning mode there was a need to find ways of organizing the study process and deliver the study materials so that it suited this mode of education. The poster describes the content and design of the programme, as well as student reactions.
\end{abstract}

Keywords: Digital libraries, curriculum, Master's programme, Sweden, international students.

\section{Background}

The 'Bologna process', whereby higher education in Europe is coordinated within a common structure of degrees, is opening up opportunities for the development of new programmes. In Sweden, the existing structure of the Magister degree (a four-year undergraduate programme) was such that the development of specialisations was rather difficult. When the opportunity arose, the Swedish School of Library and Information Science (SSLIS - a joint institute of the University of Borås and Göteborg University), started developing both undergraduate and Master's programmes.

The School had offered distance learning versions of its Magister degree for many years and it was felt that a programme aimed at the further development of practising librarians would be most likely to attract students if offered in the distance mode. There was also a desire on the part of the University of Borås to attract more participation from overseas and the distance mode, particularly using e-learning, offered the possibility of attracting students from almost anywhere in the world.

One of the first programmes to be proposed under this framework is the Master's in Library and Information Science: direction Digital Library and Information Services. It is taught in English and offered through the University's e-learning platform, Ping Pong. 
The programme was under development from 2004. The work started with a broad investigation of the competence requirements for this new area in Sweden [1] and with identifying the similar programmes developed elsewhere. As soon as the Digital Library Curriculum Project (http://curric.dlib.vt.edu/) was initiated by the University of North Carolina, Chapel Hill and Virginia Tech, SSLIS could also draw on their expertise, including evaluation of the programme presented here. SSLIS also followed the development of the ERASMUS MUNDUS project on International Digital Library Learning (DILL) that is run by Oslo University College, University of Parma and Tallinn University (http://dill.hio.no/).

In addition to the English language programme directed to a broad international community, SSLIS started working on a master's programme in Digital Services Culture, Information \& Communication for Swedish students. What specifically characterises this work is the close collaboration between SSLIS and a number of partner organizations in the library field, including the National Library of Sweden, the Gothenburg municipal library, BTJ AB (a leading supplier of media services), the University of Borås library, and the Swedish Library Association. Collaboration will continue, and be broadened to additional organisations, when the programme is up and running. The strong element of collaboration with external organizations is also the reason why the planning of the programme receives generous support from the Swedish Knowledge Foundation.

This text introduces the elements of the SSLIS Master's programmes in Digital Libraries and Services.

\section{Digital Library Elements: Programme Content}

Libraries today are predominantly 'hybrid' libraries, with traditional storage of print materials and, increasingly, access to digital resources. These resources may be held by the library itself or may be freely accessible resources from elsewhere, or access provided by subscription to, for example, encyclopaedias and e-journals. Academic libraries are also involved in the development of institutional repositories for the storage and retrieval of the research outputs of academic members of staff. Some other institutions concentrate of digitization of cultural heritage.

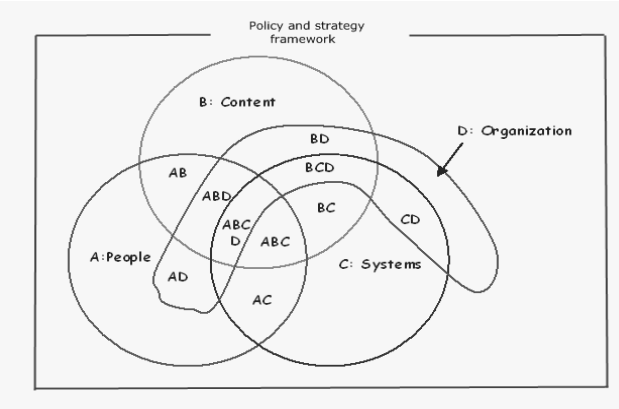

Fig. 1. Venn diagram for library and information work [2] 
The management of this diverse array of resources, therefore, calls for a variety of skills, ranging from the technical skills required for the digitization of the library's own resources (very often special collections of rare materials); to the negotiation skills required in managing subscriptions, or the financial management skills needed to run a digitization unit.

In breaking down the broad area, we drew upon Wilson's [2] Venn diagram of the scope of librarianship (see Figure 1). Within the English language Master's programme the managerial orientation is the main focus because the programme is directed to practicing librarians and information specialists. The programme seeks to educate a broad competence required for management of digital resources and services in a variety of institutions. Consequently, the irregular area labelled $\mathrm{D}$ in the diagram constitutes the core, since it identifies the organizational framework within which people are both served and (in the case of staff) managed, where content is organized, digitized and made available for use, and where systems are developed and employed to manage the digitized information resources. Space does not allow a detailed interpretation of the diagram beyond this, but the relationship of the curriculum to the diagram should become clear in the following sections. The Swedish programme goes beyond the $\mathrm{D}$ area and is directed towards more general areas marked as content (mainly, cultural heritage), systems, and framework.

The knowledge and competence developed by these Master's programmes include not only managerial capabilities, but also socio-cultural and institutional issues, theoretical and practical issues of digitization processes and information retrieval for digital libraries (including hands-on experience of project planning, mark-up languages, image editing, database management, etc.) [3]. A special effort is made to provide strong understanding of information behaviour and seeking in digital environments, human-computer interaction, digital service economics and evaluation approaches. These were competences named by the initial survey participants [1].

Each teacher involved in the project is building his or her course on the latest research on digital libraries (e.g., DELOS reference model for DLMS), and as a rule conducts related research within SSLIS (e.g., for a doctoral dissertation in digitization, open access, etc. or in a project like Sustaining Heritage Access through Multivalent ArchiviNg SHAMAN, etc.).

\section{Programme Elements: Modules}

The international programme consists of six themes, whereas the Swedish programme allows for more elective courses. Both include an individual project to be undertaken by a student in his or her own library or in one for which access is available, which then can become an intrinsic part of the Master's thesis. The content of the two programmes is slightly different, with the international programme focusing more on managerial issues and libraries, and the Swedish programme putting the emphasis on culture and communication.

The list of courses is shown below in Table 1, including the ECTS. Both programmes meet the European 'standard' of 120 ECTS.

The relations of the courses with broad areas within the Venn diagram (Fig. 1) are shown by the capital letters in the brackets for each item. 
Table 1. Courses in SSLIS Master's programmes for Digital Libraries

\begin{tabular}{|c|c|}
\hline $\begin{array}{l}\text { International Master's programme } \\
\text { LIS: direction Digital Libraries and } \\
\text { Information Services }\end{array}$ & $\begin{array}{l}\text { Master's programme LIS: direction } \\
\text { Digital Services - Culture, Information } \\
\text { and Communication }\end{array}$ \\
\hline $\begin{array}{l}\text { 1. Digital library management (15 ECTS) } \\
\text { (BCD in Venn diagram) } \\
\text { 2. Users and information practices in } \\
\text { digital environments ( } 15 \text { ECTS) (ABC) } \\
\text { 3. Information retrieval for digital } \\
\text { libraries, I and II (15 ECTS) (BC) } \\
\text { 4. Technology of digital libraries I and II } \\
\text { (15 ECTS) (C) } \\
5 . \text { Digitisation and digital preservation } \\
\text { (15 ECTS) (BCD) } \\
6 . \text { Digital library research methods (15 } \\
\text { ECTS)(Outside the diagram) } \\
\text { 7. Project work practicum (7.5 ECTS) } \\
\text { (ABCD) } \\
\text { 8. Master's thesis (22.5 ECTS) (ABCD) }\end{array}$ & $\begin{array}{l}\text { 1. Digital media in the culture and } \\
\text { information sectors ( } 7,5 \text { ECTS) (BC) } \\
\text { 2. Technology of digital libraries I }(7,5 \\
\text { ECTS) (C) } \\
\text { 3. Users and information practices in } \\
\text { digital environments (15 ECTS) (ABC) } \\
\text { 4. Project management (7,5 ECTS) } \\
\text { (BCD) } \\
\text { 5. Elective courses (22,5 ECTS) } \\
\text { 6. R \& D methods within digital services } \\
\text { (15 ECTS)(Outside the diagram) } \\
\text { 7. Work place-related project (15 ECTS) } \\
\text { (ABCD) } \\
\text { 8. Master's thesis (30 ECTS) (ABCD) }\end{array}$ \\
\hline
\end{tabular}

Both programmes are starting in autumn 2009, however, the international Master's programme has already piloted several courses in the distance mode in 2008 and in spring of 2009 for international students from Europe, Asia, Australia and Africa.

\section{Content Delivery}

This part includes examples of the course pages developed for the international Master's programme.

As noted earlier, the programme uses the Ping Pong virtual learning environment. The screen-shot below shows the initial page for one of the courses - Users and information practices in digital environments.

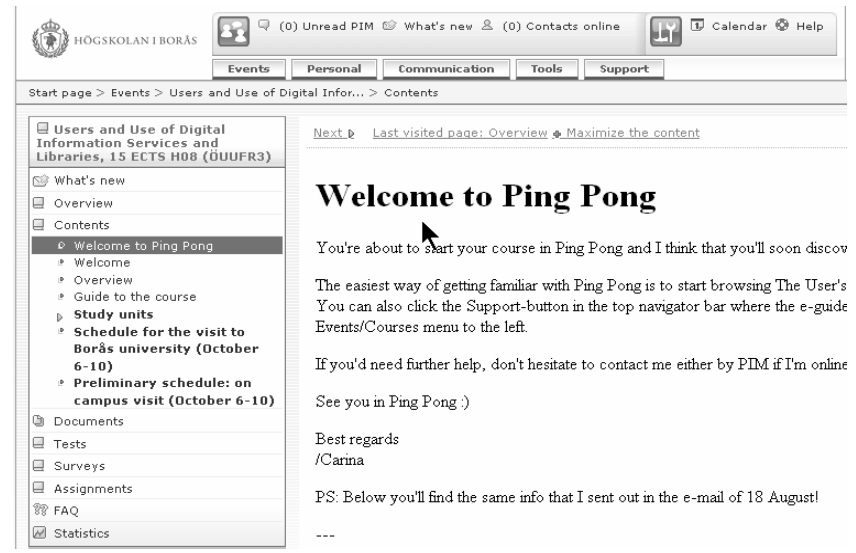

Fig. 2. Initial page in a course of the Programme (e-learning platform Ping Pong) 


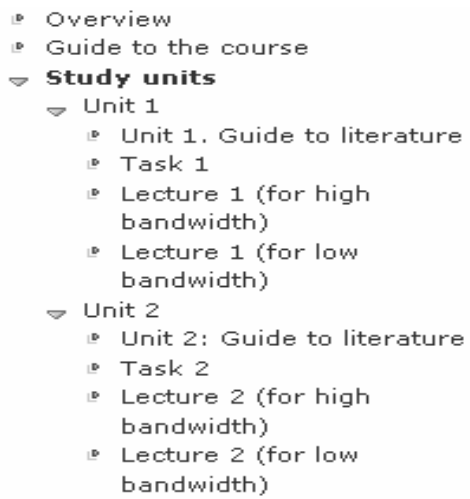

Fig. 3. A side bar showing the types of teaching materials

The 'study units' are the individual units of the course and each study unit consists of a number of elements, as shown in the next screen-shot.

The programme consists not only of traditional documentary learning materials, but also includes videotaped lectures. Ping Pong also includes facilities for discussion among students and with teachers and a variety of other virtual learning functions. The teachers are using a combination of word-processed files and Web pages. The following screen-shot shows one of the Web pages written for the unit on managing digital libraries.

Web pages include a guide to the literature, materials for discussions, links to relevant Web sites and lists of literature with an indication of where to find it (the links to the texts that are in the public domain are embedded).

The programme also includes two residential periods each year. This provides an opportunity for the students to meet their classmates and teachers, to attend lectures, to engage in face-to-face discussions and to experience hands-on learning in the classroom. The latter is an essential part in the courses related to technology and information retrieval.

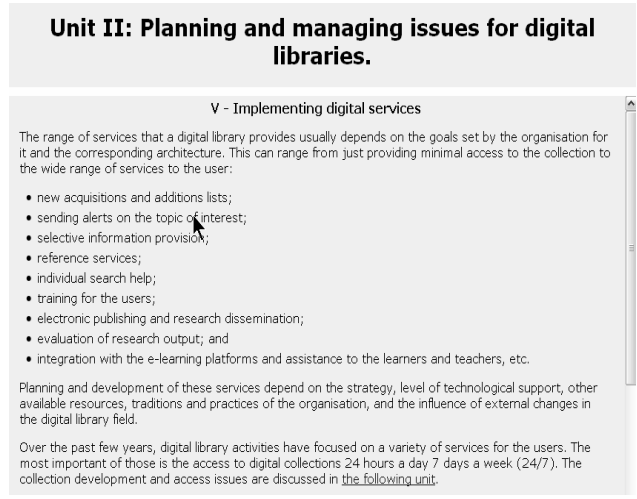

Fig. 4. A Web page in a course 


\section{Student Reactions}

Most of the students who have studied two courses in the international programme have succeeded in completing the first one and, at the time of writing, are studying the third unit of the second course. They have noted the logical link between the courses. Different ways in which the course materials are delivered in both courses help them to stay motivated and stimulate their interest in the process of study.

Students have deemed the schedule for the delivery of the tasks to be demanding but realistic in terms of planned reading and working. It has also been appreciated that the deadlines, though set, are not cast in iron and students have felt that the schedule has been reasonably flexible.

The students have appreciated the service of the University Library and Learning Resources as the free access to the databases is very important to them. The provision of the lecture texts on the platform in Word and PowerPoint formats has been regarded as a feature of usability, especially by those who have to pay for the network connection time. The use of WebCite [4] for the online material is useful as it helps to reduce the problem of broken links for the students (and teachers as well).

\section{References}

1. Maceviciute, E.: Edukacja dla potrzeb bibliotek cyfrowych i informacji. In: M. Kocójowa (ed.), Profesjonalna informacja w internecie, pp. 26--34. Wydawnictwo universitetu Jagiellońskiego, Kraków (2005)

2. Wilson, T.D.: Mapping the curriculum in information studies. New Library World 102(11/12), 436-442 (2001)

3. Dahlström, M., Doracic, A.: Digitization education: courses taken and lessons learned. D-Lib Magazine 15(3/4) (2009), http://www.dlib.org/dlib/march09/dahlstrom/03dahlstrom.html

4. WebCite, http://www.webcitation.org/ 